\title{
Intraspecific variation in metal tolerance modulate competition between two marine diatoms
}

\author{
Björn Andersson (iD ${ }^{1 凶}$, Anna Godhe ${ }^{1}$, Helena L. Filipsson (D) $^{2}$, Linda Zetterholm ${ }^{1}$, Lars Edler ${ }^{3}$, Olof Berglund (D) ${ }^{4}$ and Karin Rengefors ${ }^{4}$
}

(c) The Author(s) 2021

Despite widespread metal pollution of coastal ecosystems, little is known of its effect on marine phytoplankton. We designed a cocultivation experiment to test if toxic dose-response relationships can be used to predict the competitive outcome of two species under metal stress. Specifically, we took into account intraspecific strain variation and selection. We used $72 \mathrm{~h}$ dose-response relationships to model how silver $(\mathrm{Ag})$, cadmium $(\mathrm{Cd})$, and copper $(\mathrm{Cu})$ affect both intraspecific strain selection and competition between taxa in two marine diatoms (Skeletonema marinoi and Thalassiosira baltica). The models were validated against 10-day coculture experiments, using four strains per species. In the control treatment, we could predict the outcome using strain-specific growth rates, suggesting low levels of competitive interactions between the species. Our models correctly predicted which species would gain a competitive advantage under toxic stress. However, the absolute inhibition levels were confounded by the development of chronic toxic stress, resulting in a higher long-term inhibition by $\mathrm{Cd}$ and $\mathrm{Cu}$. We failed to detect species differences in average $\mathrm{Cu}$ tolerance, but the model accounting for strain selection accurately predicted a competitive advantage for $T$. baltica. Our findings demonstrate the importance of incorporating multiple strains when determining traits and when performing microbial competition experiments.

The ISME Journal (2022) 16:511-520; https://doi.org/10.1038/s41396-021-01092-9

\section{INTRODUCTION}

The world's oceans are increasingly impacted by human activities causing climate change, eutrophication, and pollution [1]. Fitness of marine organisms can be directly affected by these environmental changes or indirectly through effects on competitors at the same trophic level, resource availability, and predation. Organisms may also evolve to compensate for fitness loss. Ecological and evolutionary effects on slow-growing organisms take time to develop, but microbial communities respond rapidly to environmental perturbation. Under toxic stress, sensitive microbial species are rapidly displaced by more tolerant ones [2-4], and in polluted soils and ponds, this generally reduces both diversity and ecosystem functionality [5-7]. Yet, our understanding of the structural effects of toxic compounds on marine phytoplankton communities is limited, despite their global ecological importance $[8,9]$.

On a global scale, the Baltic Sea is amongst the most perturbed marine systems. This sea currently experiences ocean acidification, warming, eutrophication, hypoxia, and pollution, which are projected to affect other coastal areas in the future [10]. Amongst other problems, this has led to bioaccumulation of heavy metals and organic pollutants in higher trophic levels of the marine food chain, but less is known about the effects of pollutants (macronutrients excluded) on the Baltic Sea microbial plankton community [11]. In seas and coastal waters, ambient pollution of copper (Cu), cadmium (Cd), and silver (Ag) may have structural effects on marine phytoplankton communities, although this has primarily been observed through the exclusion of highly sensitive cyanobacteria species [12-14]. In contrast, marine diatoms are considered to be more resilient to heavy metals [15], although observations are heavily biased towards model species in culture, and little is known about intraspecific variation. However, we recently observed that individual strains of a diatom population of Skeletonema marinoi Sarno and Zingone inhabiting the Cu miningaffected inlet of Gåsfjärden, on the Swedish Baltic Sea coast, displayed elevated tolerance to $\mathrm{Cu}$ (as well as towards several other metals), compared to a non-polluted reference population (Gropviken [16]). Based on silica frustules preserved in the Gåsfjärden sediment, it also appears that $S$. marinoi was severely depressed in relative abundance during the peak mining activity (circa 1600 to $1920 \mathrm{CE}$ ), and have recolonized the inlet since [17]. Changes in phytoplankton community composition have effects on higher trophic levels due to selective feeding mechanisms by zooplankton [18], and these observations suggest that the composition of costal diatoms in the Baltic Sea may be affected by metal pollution.

Variance in metal toxicity among marine phytoplankton species has mainly been characterized in the form of acute dose-response curves (72-96 $\mathrm{h}$ exposure) for a limited number of cultured model strains (e.g., $[15,19])$. In contrast, traits such as light and thermal tolerance, $p \mathrm{CO}_{2}$ responses, nutrient uptake kinetics, and predator defenses, have been more widely characterized and found to vary

${ }^{1}$ Department of Marine Sciences, University of Gothenburg, Göteborg, Sweden. ${ }^{2}$ Department of Geology, Lund University, Lund, Sweden. ${ }^{3}$ Doktorsg. 9d, Weaq Lab, Ängelholm, Sweden. ${ }^{4}$ Department of Biology, Lund University, Lund, Sweden. ${ }^{凶}$ email: bjorn.andersson@marine.gu.se

Received: 8 April 2021 Revised: 9 August 2021 Accepted: 12 August 2021

Published online: 26 August 2021 
significantly not only between phytoplankton taxa [20-22], but also among strains within local populations of species [23-26]. A potential limitation of these observations is that the majority are based on culture experiments on single strains in mono-culture (e.g., [24, 27-29]), which often fails to predict outcomes of cocultivation experiments because of species or strain interactions in the shared aqueous environment [30-33]. Two well-known examples of such interactions are allelopathic chemical production [34] and luxury consumptions of nutrients [35]. Consequently, there is a need to further evaluate strain-based phenotypic observations in more complex biological settings.

We designed a co-cultivation experiment to test if strain-specific toxic dose-response relationships [36] can be used to construct deterministic models of how well $S$. marinoi compete with a related species (Thalassiosira baltica [Grunow] Ostenfeld) under metal stress ( $\mathrm{Ag}, \mathrm{Cd}$, and $\mathrm{Cu}$ ). To this end we used strain specific growth rates and inhibition coefficients to predict how selection on strains (four per species) modulates competition. The model was challenged against empirical observations during 10 days (10-20 generations) of semicontinuous co-cultivation. Similar models have been created to explore how differences in ecological traits such as temperature, nutrients, diversity, predatory defense, and light responses, structure phytoplankton communities [21, 22, 37-40]. However, to our knowledge, our model is the first that predicts how toxic responses modulate both strain selection and competition. We were especially interested in resolving if $\mathrm{Cu}$ toxicity affects fitness negatively in S. marinoi, since this provides a plausible ecological mechanism explaining the demographic patterns observed at the mining exposed Gåsfjärden population [16, 17] of the Baltic Sea. We chose to contrast $S$. marinoi with $T$. baltica since these two species comprise about $50 \%$ of the standing diatom biomass in the Baltic Sea and generally overlap temporally in abundance, suggesting that they are both ecologically important and natural competitors (Supplementary Fig. S1). By comparing the model's outcome against the co-cultivation experiment, we explored if competitive interactions, strain selection, acclimatization [41,42], or development of chronic stress [43] are important processes modulating species competition under toxic stress.

\section{METHOD \\ Sampling sites, growth media, and physiological measurements}

Four strains each of non-axenic S. marinoi and T. baltica were isolated as single chains/cells from Gropviken (GP; $58^{\circ} 19.92^{\prime} \mathrm{N} 16^{\circ} 42.35^{\prime} \mathrm{E}$ ) sediment resting stages as described previously [44]. We chose to conduct the competition experiment on strains from our previous reference site (GP), rather than the mining-affected site Gåsfjärden (VG), to assess tolerance differences in the more pristine of the two populations (Fig. 1). Experiments were performed at $16^{\circ} \mathrm{C}$ under $180 \mu \mathrm{mol}$ photons $\mathrm{m}^{-2} \mathrm{~s}^{-1}$ of photosynthetically active radiation (PAR): at 12:12 $\mathrm{h}$ light-dark cycles. Light was supplied by LUMILUXV Cool daylight L 36 W/865 light bars (OSRAM, Munich, Germany) and PAR was measured using a LI-COR ${ }^{\circ}$ LI-1400 lightmeter with a scalar US-SQS/L detector (Walz, Effeltrich, Germany). In addition to the laboratory experiment, we analyzed monitoring data on $\mathrm{Cu}$ and $\mathrm{Cd}$ concentration and the seasonal phytoplankton bloom dynamics of a coastal site of the Baltic Sea, with specific emphasis on S. marinoi and $T$. baltica bloom dynamics (Supplementary Appendix A, C).

Site-specific seawater (salinity 7) was sterile-filtered (Sarstedt's [Helsingborg, Sweden] $0.2 \mu \mathrm{m}$ polyethersulfone membrane filter) and amended with $\mathrm{f} / 2$ concentrations of inorganic nutrients [45], with addition of $106 \mu \mathrm{M}$ $\mathrm{SiO}_{2}$. In the $\mathrm{f} / 2$ media iron is chelated with $11.5 \mu \mathrm{M}$ EDTA, which prevents iron precipitation but also reduces metal toxicity [46]. In the experiments, we subjected cultures to the average EC50 (effective concentration inhibiting growth rate by $50 \%$ ) determined across all eight strains in Andersson et al. [16] which corresponded to 5.5, 9.7, and $0.046 \mu \mathrm{M}$, for $\mathrm{Cd}$ (II), $\mathrm{Cu}(\mathrm{II})$, and $\mathrm{Ag}(\mathrm{I})$, respectively $(\mathrm{Cd}, \mathrm{Cu}$ and $\mathrm{Ag}$, from here on). Metal amendment was done with acidified ( $\mathrm{pH} 2), 100 \mu \mathrm{M}$ stock-metal solution to growth media three hrs $( \pm 30 \mathrm{~min})$ prior to the addition of cells. The absolute concentration of $\mathrm{Cd}, \mathrm{Ag}$, and $\mathrm{Cu}$ in stocks was quantified as described in [16] and chemicals were of analytical grade from Sigma Aldrich (St. Louis, MO, U.S.).

Culture biomass was routinely measured using in vivo chlorophyll $a$ (chl a) fluorescence (RFU [relative fluorescence units]) using a Varioscan Flash Multimode Reader (ThermoScientific, Waltham, MA, U.S.), as described in [24]. RFU was measured midway into the light cycle $( \pm 1 \mathrm{~h})$, and in the mono-strain cultures RFU measurements were used to calculate growth rates and inhibition coefficients (Eqs. 1, 2 below). During co-cultivation, 1 $\mathrm{mL}$ samples were preserved with $5 \mu \mathrm{L}$ acidified Lugol's solution, and microscopic observations were made using an Axiovert 135, Zeiss. Two hundred cells per species and samples were counted, or the total abundances in $1 \mathrm{~mL}$ if the densities were too low. Geometrical sizes of cells were computed based on dimensions of 20 cells per sample $(\times 400$ magnification) according to [47]. For the two diatom species in this study, RFU is most closely linked to biomass expressed as surface area [16] and we choose to utilize this unit to describe relative abundances and to compute species-specific growth rates under co-cultivation.

Pulse amplitude modulation (PAM) fluorometry was used to assess the physiological effect of metal treatment on the photosynthetic capacity of the cultures. The advantage of PAM fluorometry, in contrast to growth rate estimates, is that it can detect physiological stress instantaneously, without relying on two or more measurements over time. A Phyto-PAM [48] was used to measure temporal changes in the maximum quantum yield of photosynthesis $\left(\mathrm{F}_{\mathrm{V}} / \mathrm{F}_{\mathrm{M}}\right)$. We used the $650 \mathrm{~nm}$ excitation light channel, and set the measurement frequency to $16 \mathrm{~Hz}$ to minimize actinic light effects in dark samples $\left(<2 \mu \mathrm{mol}\right.$ photons $\left.\mathrm{m}^{-2} \mathrm{~s}^{-1}\right)$. Samples $(1.5 \mathrm{~mL})$ were darkacclimatized for $10 \mathrm{~min}$, to relax any quenching of chl $a$ fluorescence and establish $F_{0}$, after which a $200 \mathrm{~ms}$ long, $10,000 \mu \mathrm{mol}$ photons $\mathrm{m}^{-2} \mathrm{~s}^{-1}$ strong, saturating pulse was used to elicit $F_{M} \cdot F_{v} / F_{M}$ was computed as $\left(F_{M}-F_{0}\right) / F_{M}$.

\section{Modeling outcome of selection under metal stress}

The most widely used proxy for fitness in microalgae is exponential growth rate under a specific environmental condition. Exponential growth is also a condition that can be maintained and validated in an experimental setting [49], and it is the state of growth phytoplankton experience prior to the onset of nutrient depletion [39], once grazing mortality is corrected for [50]. Specific growth rates $(\mu)$ were computed using naturally logtransformed increments in density:

$\mu=L N\left(D_{t 1} / D_{t 0}\right) /\left(t_{1}-t_{0}\right)$

where $D_{t 1}$ and $D_{t 0}$ corresponds to the final and initial culture density and $t_{1}-t_{0}$ the time difference between the measurements in days.

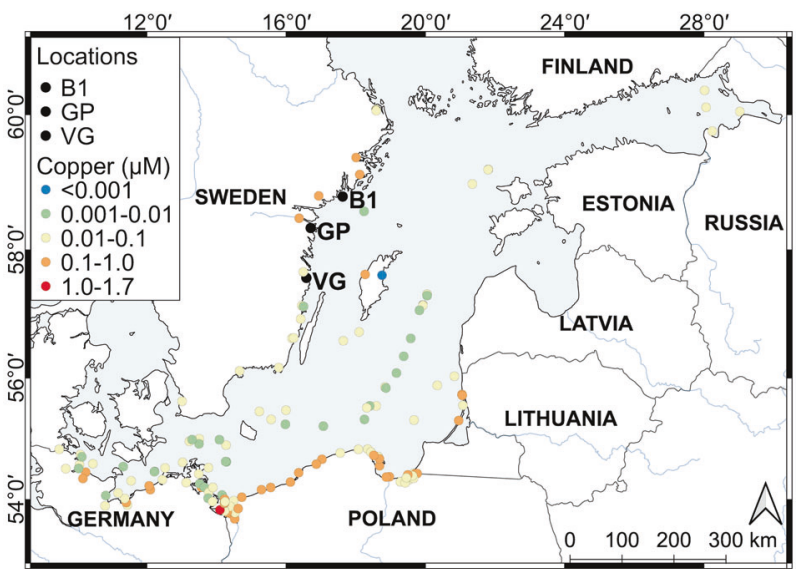

Fig. 1 Map of the southern Baltic Sea showing sampling locations and monitoring data of Copper concentrations. Locations are Askö (B1: phytoplankton monitoring data), Gropviken (GP: retrieval site of strains used in this study), and Gåsfjärden (VG: copper mining site with elevated metal tolerance amongst $S$. marinoi strains compared with GP [16]). Colored dots show reported monitoring data of surface water concentrations of copper from ICES, IVL, and SLU databases. Note that for sites with multiple measurements only the maximum value is shown (see Appendix A for full data and method description). 
We used standardized acute $72 \mathrm{~h}$ toxic dose-response relationships to predict strain specific inhibition of growth rates by each metal [36]. Relationships for $\mathrm{Ag}, \mathrm{Cd}$, and $\mathrm{Cu}$, (as well as $\mathrm{Co}, \mathrm{Ni}, \mathrm{Pb}$, and $\mathrm{Zn}$ ) were generated for the eight strains. A detailed description of the method can be found in [16]. From this data we extracted standardized (0-1) inhibition coefficients for the specific concentration of the metal assayed $\left(I_{M C[72 h]}\right)$ which combined with strain-specific growth rate estimates, can predict growth rate under the assay conditions:

$\mu_{M C}=\mu-\left(\mathrm{I}_{M C(72 h)} \times \mu\right)$

For a specific strain, $\mu_{M C}$ corresponds to the growth rate under exposure to the metal $\mathrm{M}$ at concentration $\mathrm{C}$. Long-term deviations between observed data and the prediction from Eq. (2) can be used to infer if acclimatization (Eq. (2) will underestimate growth rates) or chronic toxic effects (Eq. (2) will overestimate growth rates), are important long-term processes. By using $\mu_{M C}$ and rearranging Eq. (1) we made a deterministic model of how metal stress affects growth of a culture with an initial density of $D_{t 0}$ as a function of time $(t)$ :

$\mathrm{D}_{t}=\mathrm{D}_{t 0} \times e^{\left(\mu_{\mathrm{MC}} \times t\right)}$

The model can be extended to include species competition and intraspecific selection, i.e., a 'Competition-Selection model', by assuming that the individual species/strains do not modulate their own or other strains/species growth when co-cultivated (hereafter referred to as competitive interaction). When describing outcomes of competition and selection, we used relative density (RD) of species/strain $i$ at time $t$ with respect to the total number of species/strain $i-j$ [25], which assuming that the start densities of all strains are the same, can be predicted as:

$\mathrm{RD}_{(i) t}=e^{\left(\mu_{\mathrm{MC}} \times t\right)} / \sum_{i-j} e^{\left(\mu_{\mathrm{MC}} \times t\right)}$

From this derivation we predicted the evolutionary response of the populations' growth rate in response to selection by summarizing the individual contribution of all strains $\left(\mu_{\mathrm{i}-\mathrm{j}}\right)$ to the population $\left(\mu_{\mathrm{Pop}}\right)$, given their predicted relative density at a given time $(\mathrm{t})$.

$\mu_{(P o p) t}=\sum_{i-j}\left(\mathrm{RD}_{t} \times \mu\right)$

For Eqs. (4), (5) to be valid we make two important assumptions. First, we assume indefinite, nutrient replete, exponential growth, which can only be achieved using a low density semicontinuous, or turbidostatic, cultivation approach [49]. Secondly, the Competition-Selection model assumes no competitive interaction that modulates growth rates (i.e., competitive interaction) or the toxicity of metals. As a contrast to the CompetitionSelection model, we also predicted the competitive outcome on a Strainby-Strain basis (16 predictions based on a T. balticaS. marinoi strain matrix), which illustrates how individual strain variability in tolerance influences the competitive outcome.

\section{Competition experiment}

A schematic design of the competition experiment is shown in Fig. S2 and described in detail in Appendix B. Briefly, the experiment strived to subject the co-cultures (four strains each of S. marinoi and T. baltica) to Ag, Cd, and $\mathrm{Cu}$ stress, corresponding to the average EC50 amongst all eight strains. Nutrient replete, exponential growth was maintained through semicontinuous cultivation with serial dilution every 3 to 4 days according to [49]. To avoid nutrient limitation the maximum density was maintained below 30 $\mathrm{mm}^{3}$ biovolume cells $\mathrm{L}^{-1}$ media [16]. We monitored culture responses until one species was diluted to extinction in the control (defined as $<1$ cell $\left.\mathrm{mL}^{-1}\right)$, which took 10 days. Microscopy observations were done in connection with dilution on days $0,4,7$, and 10 . In parallel with the start of the competition experiment, we also made growth rate observations and metal inhibition measurements of the strains in mono-cultures $(N=2)$ in 1 $\mathrm{mL}$ of each treatment media (24-well microplates, Polystyren, Falcon).

\section{Statistical analyses and model implementation}

Statistical analyses and model predictions were computed in R v. 3.6 .2 [51]. Dose-response relationships and predictions of inhibition coefficients were generated using the drc package v. 3.0-1 [52] with Type 1 Weibull function [W1.2] for Cd and Type 2 Weibull [W2.2] for Ag and Cu [16]. Plotting and Model fittings were done in the package ggplot2 v. 3.2.1 [53]. Species differences in average growth and inhibition were tested using Welch $t$ test, which does not assume homogeneous variances, using square-root transformed data. Differences in variance of traits between the species was assessed using the F-test. Paired $t$ tests were used to test if individual strains varied in inhibition responses between the dose-response based prediction and the mono-culture observations. Linear mixed effects (LME) models were used to analyze the outcome of competition experiments and to test if growth rate, inhibition, and $F_{V} / F_{M}$ changes significantly between species, metals, and over time (fixed factors), using the nmle package [54] version 3.1149. Replicate bottles were treated as random factors to account for pseudoreplication. For significant factors, post hoc tests were performed on hypothesis related comparison, not in a full factorial design, using pairwise Students $t$ tests with Bonferroni corrected $p$ values to account for multiple testing. The datasets generated during the study are available in the Dryad repository (doi.org/10.5061/dryad.280gb5mq9) and the CompetitionSelection models code can be accessed through Git-Hub (https://github. com/Bearstar85/Selection_Competition_2021).

\section{RESULTS}

\section{Strain variability in growth and metal inhibition}

To validate the accuracy of the dose-response relationships, we contrasted dose-response predicted and observed inhibition on a strain basis (Fig. 2). In mono-culture, S. marinoi had an intrinsically higher growth rate than $T$. baltica under our assay conditions (Fig. 2A). For Ag, three T. baltica strains exhibited a stronger relative inhibition in the current assay than predicted (range 0.54-1.5 compared with 0.24-0.4, Fig. 2B). The fourth strain of $T$. baltica (TB_GP2-4_13) suffered a drastic decline in mono-culture growth rate and also became more sensitive to $\mathrm{Ag}, \mathrm{Cd}$, and $\mathrm{Cu}$ than predictions from the dose-response data. All four S. marinoi strains were less inhibited by $\mathrm{Cd}$ than $T$. baltica, and the strain prediction from previous data closely matched the observed inhibition, except that three T. baltica strains experienced negative growth (Inhibition $>1$ ), which the function cannot predict (Fig. 2C, Table S1). For $\mathrm{Cu}$, we observed large and overlapping inter- and intraspecific variability in monoculture inhibition (Fig. 2D), and the species' averages did not differ statistically using either assay approach.

\section{Modeling the outcome of competition and selection under metal stress}

To predict the outcome of competition between the two species with potential for intraspecific selection, we constructed a Competition-Selection model that gave strains unique fitness features based on the predicted inhibition coefficients (Eqs. (4), (5)). In the Competition-Selection model it is not only the average, but also the variance between strains of a species that determine the competitive outcome. T. baltica had more variance in both basic growth rate (coefficient of variance [C.V.] 0.56 versus $0.08, \mathrm{~F}$ test, $p=0.02$ ) and, with the exception of predictions for $\mathrm{Cd}$, trends of higher C.V. in all inhibition observations (F-test, $p=0.06$ for $\mathrm{Ag}$ predicted, Ag observed, and Cd observed: Table S1).

The Competition-Selection model predicted that it would take 4 to 5 days in the control treatment for $S$. marinoi to account for $>99 \%$ of the total biomass (Fig. S3A), due to its higher growth rate (average $1.55 \pm 0.12$, compared with $0.55 \pm 0.31$ day $^{-1}$ for $T$. baltica). The Competition-Selection model also predicted that $S$. marinoi strain SM_GP2-4_06, with a growth rate of $1.75 \pm$ 0.07 day $^{-1}$, would account for $65 \%$ of the total S. marinoi biomass by day 10 (Fig. S3A). Under Ag stress, the Competition-Selection model predicted that $T$. baltica would rise close to competitive exclusion after 10 days ( $>99 \%$ of biomass) with an advantage for strain TB_GP2-4_09 and TB_GP2-4_16 (Fig. S3B). For Cd, T. baltica was predicted to be suppressed more rapidly than in the control, and that SM_GP2-4_06 would dominate the S. marinoi population (Fig. S3C), driven by both comparatively high growth rate and low Cd inhibition (Fig. $2 \mathrm{C}$ and Table S1). However, the dose-response curve of SM_GP2-4_06 displayed a pronounced degree of hormesis (stimulation of growth) at low Cd concentration (Fig. S4), 

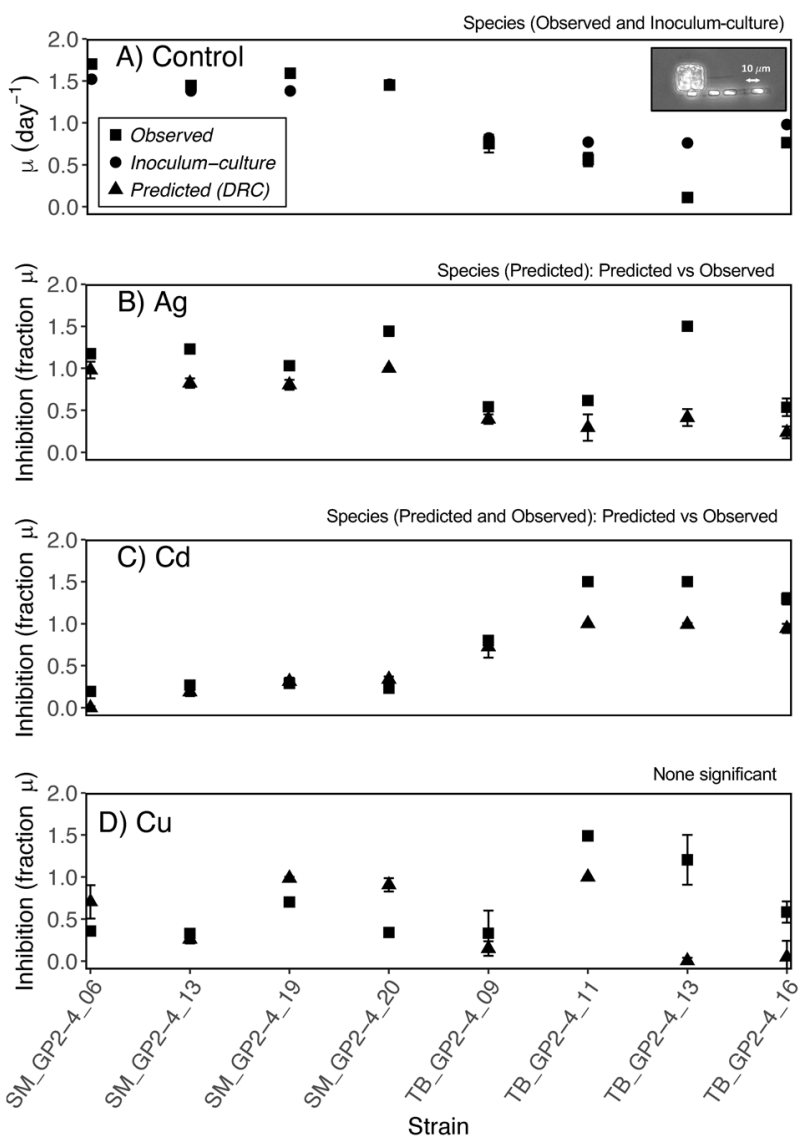

Fig. 2 Strain variability in model parameters of S. marinoi (SM: smaller chain forming cells) and $T$. baltica (TB: larger solitary cell). (A) specific growth rate without toxic stress, and inhibition of growth rates when exposed to (B) silver $[0.046 \mu \mathrm{M}]$, (C) cadmium $[5.51 \mu \mathrm{M}]$, and (D) copper [9.73 $\mu \mathrm{M}]$. Squares indicate observations in mono-cultures and triangles the inhibition that was predicted using dose-response (DRC) measurements from [16]. Circles in (A) show inoculum-culture growth rate, which was observed in the subculturing step prior to seeding the Competition experiment. Confidence intervals for Observed data show range $(N=2)$, and for the Predicted the model estimates with $95 \%$ confidence interval. When error bars are not visible, they are confined within the symbols. Significant differences $(p<0.05)$ are indicated on top of each panel based on Welsh $t$ test (betweent Species) or paired $t$ test (between Predicted vs. Observed inhibition estimates). Data were square-root transformed for statistical testing.

which caused an underestimated predicted inhibition value, compared with the mono-culture observation (Table S1). Under $\mathrm{Cu}$ stress the Competition-Selection model suggested that $S$. marinoi still holds a small competitive advantage over T. baltica, but that a higher tolerance in two T. baltica strains slows down the competitive exclusion process (Fig. S3D).

\section{Competition without stress}

To validate the predictions from the Competition-Selection model we performed a competition experiment where all eight strains were mixed at equal RFU densities and subjected to $\mathrm{Ag}, \mathrm{Cd}$, or $\mathrm{Cu}$ stress, and a control treatment. For clarity, we have chosen to structure the results of the competition experiment individually for the four treatments. The changes in community density (RFU), and $F_{V} / F_{M}$, over the course of the experiment are shown in Fig. 3.

In the control treatment, the relative biomass between the two species changed as predicted from the Competition-Selection model during the 10 days (Fig. 4A). As expected from strain selection, growth rates also increased over time in both species
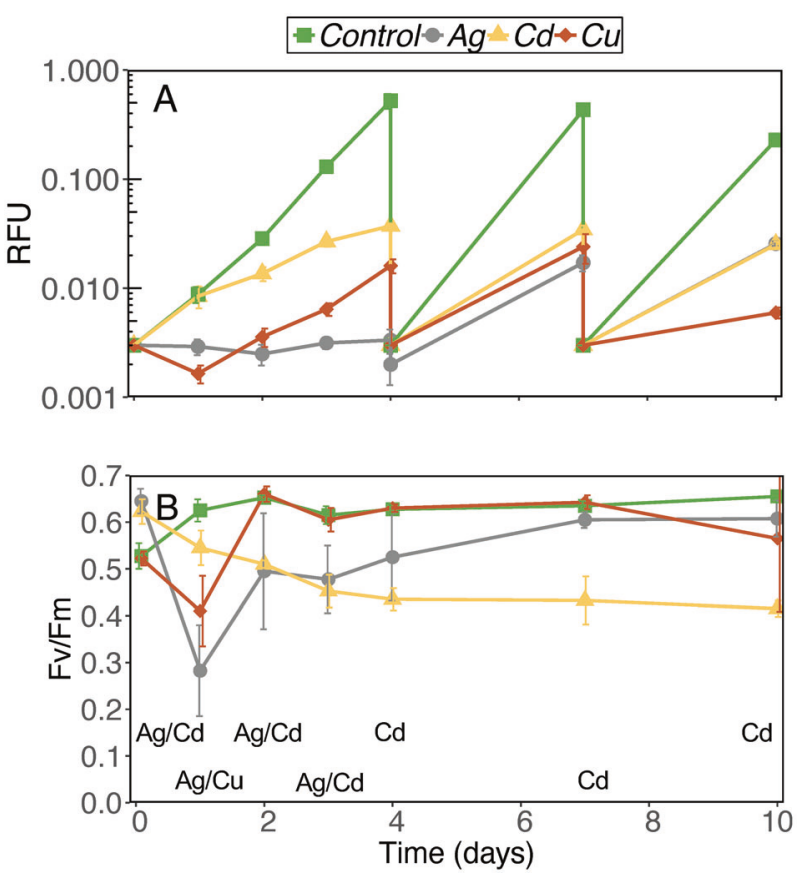

Fig. 3 Changes in community (S. marinoi and T. baltica strains) density (A) measured as relative chlorophyll $a$ fluorescence units (RFU) and maximum quantum yield of photosystem II (B) during the competition experiment. The community was semicontinuously diluted to 0.003 RFU before the end of exponential growth which occurs at $0.5 \mathrm{RFU}$ in S. marinoi (which dominated the control) and 0.08 in T. baltica. Linear mixed effects models of $F_{V} / F_{M}$ identified significant differences between Metals $\left(F_{(3,12)}, p<0.0001\right)$, Time $\left(\mathrm{F}_{(6,72),}, p<0.0001\right)$ and an interaction Metal $\times$ Time $\left(\mathrm{F}_{(18,72), p<}\right.$ $0.0001)$. Metal names at the bottom of (B) indicate statistical differences relative to the control, based on post hoc test $(p<0.05)$. Error bars show S.D. $(N=4)$, and when error bars are not visible, they are confined within the symbols.

and reached a peak at rates close to model predictions (Fig. 5). In the semicontinuous growth mode, culture densities oscillated between 0.4 and $30 \mathrm{~mm}^{3}$ biovolume $\mathrm{L}^{-1}$ media, incorporating the densities range observed during peak bloom conditions (Fig. S1). These results show that, although the two species were allowed to physically interact during co-cultivation, this did not modulate the growth rate of either species under nutrient replete conditions and realistic cell densities.

\section{Competition under silver stress}

Based on RFU the Ag treatment had an immediate and severe detrimental effect on co-culture growth during the first 4 days. After this period growth improved, albeit at a slower rate than in the control (Fig. 3A). The $F_{V} / F_{M}$ showed a similar pattern of stress follow by recovery, and decreased significantly to 0.3 after $24 \mathrm{~h}$, and then made a gradual recovery until day 4 , when it could no longer be statistically differentiated from the control (Fig. 3B).

Based on both the Competition-Selection model and all Strainby-Strain predictions, Ag stress was expected to consistently modulate competition in favor of $T$. baltica. This did happen, but all predictions underestimated the observed rate (Fig. 4B). One contributing factor was that the Ag Competition-Selection model utilized standardized inhibition coefficients and cannot predict negative growth (inhibition $>1$ ), which for S. marinoi, averaged 1.2 across the 10 days (Table 1). The Competition-Selection models predicted an increase in $T$. baltica growth rate under Ag stress, which was realized in the experiment (Fig. 5C, D). Inhibition could not be statistically ascertained compared to the control (average inhibition 0.095 post hoc test, $p>0.68$, Table 1), which was lower 

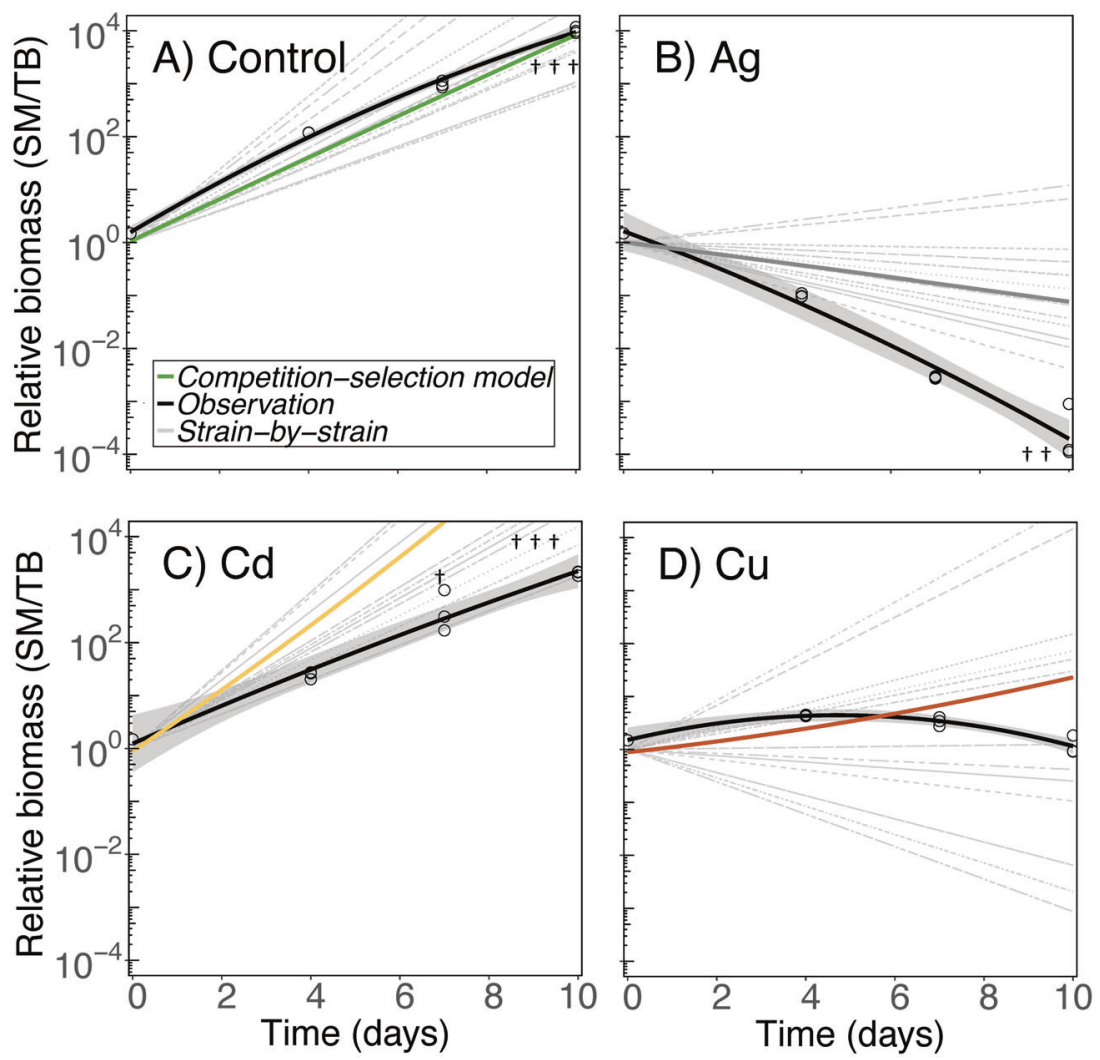

Fig. 4 Observed and modeled changes in relative biomass (based on cellular surface area) of S. marinoi (SM) over T. baltica (TB) during the competition experiment. (A) shows control conditions, (B) silver stress, (C) cadmium stress, and (D) copper stress. Open circles correspond to observational microscopy data $(N=3)$, which have been fitted with a second order polynomial function, and $95 \%$ confidence intervals (black solid lines). When a species became extinct it was represented as the lowest detection limit (i.e., $1 \mathrm{cell}^{\mathrm{mL}}{ }^{-1}$ ) and such replicates are flagged with a single cross in the figure. Gray thin lines show modeled outcome of competition between individual strains in a factorial design ( $4 \times 4$ strains of each species). The Competition-Selection model (solid-colored lines) utilizes parameters of all eight strains simultaneously and allows for intraspecific selection. The model input parameters are shown in Table S1.

than the strain specific observation (range 0.24-0.4 [predicted] and 0.54-1.5 [observed]; Table S2).

\section{Competition under cadmium stress}

In contrast to $\mathrm{Ag}, \mathrm{Cd}$ had no effect on either RFU or $\mathrm{F}_{\mathrm{V}} / \mathrm{F}_{\mathrm{M}}$ during the first $24 \mathrm{~h}$ exposure. After $24 \mathrm{~h}$ both growth and $\mathrm{F}_{\mathrm{V}} / \mathrm{F}_{\mathrm{M}}$ declined, and by day 4 and beyond the $F_{V} / F_{M}$ stabilized at 0.45 , compared with 0.65 in the control (Fig. 3). Cd exposure also induced morphological changes in both species. The cytoplasm of many $T$. baltica cells became darker under the light microscope, a sign of resting stage formation. Other $T$. baltica cells became elongated and on day 7 the average diameter:length ratio was $0.7( \pm 0.3)$ compared with $1.2( \pm 0.2)$ at day 0 . Conversely, many S. marinoi cells became shorter and rounder with time, and the average diameter:length ratio increased from $0.4( \pm 0.1)$ to $0.5( \pm 0.2)$.

The Competition-Selection model predicted that $\mathrm{Cd}$ stress would speed up the increase in relative biomass of $S$. marinoi, but this did not occur (Fig. 4C). Instead, a chronic toxic response developed in S. marinoi manifested as a decrease in growth rate over time (Fig. 5D). However, the outcome was still competitive exclusion of $T$. baltica within 10 days of co-cultivation.

\section{Competition under copper stress}

The $\mathrm{Cu}$ treatment caused an irregular temporal response, with a decrease in RFU and $F_{V} / F_{M}$ during $24 \mathrm{~h}$ post inoculation, after which net positive growth resumed (Fig. 3). By day 2, the $F_{V} / F_{M}$ had recovered to the control baseline of 0.65 . This could be interpreted as an acclimatization response, but in a follow-up experiment we show that this was because the toxicity of $\mathrm{Cu}$ decreases for at least five hrs after it has been added to media (Fig. S5A), and cells were added after three hrs while Cu appeared to still be equilibrating with the media. No apparent changes in morphology compared with the control were observed in either species.

In the three separate experiments (dose-response relationship, mono-cultures, and during competition), the species differences in $\mathrm{Cu}$ tolerance could not be distinguished by comparing the average growth rate between the two species, using traditional $t$ or post hoc tests (Tables S1, 1). However, the trend of variance in tolerance was higher in $T$. baltica, not only for $\mathrm{Cu}$, but across all metals (Table S1). In the competition experiment, $\mathrm{Cu}$ stress favored the $T$. baltica population, while the 16 Strain-by-Strain predictions resulted in a broad spectrum of variable competitive outcomes (Fig. 4D). Overall, the Competition-Selection model came close to predicting changes in relative biomass of the two species under co-cultivation (Fig. 4D), even though chronic toxic effects set in after day 7 , and growth rates of both species collapsed $<0$ (Fig. 5B, D).

We conducted a database search for metal concentrations in seawater to test if, where, and when, Cu may exert toxic effect on Baltic Sea diatoms (Appendix C). To enable a reasonable comparison between the observed inhibitory data of this study and the environmental samples, we removed EDTA from the $f / 2$ media and gathered complementary dose-response curves. As expected, this lowered the EC05 (effective concentration inhibiting growth rate by 5\%) in S. marinoi from 5.3 to $0.26 \mu \mathrm{M}$ (Fig. S5B). We used this lower observation as an indicator of the concentration at which $\mathrm{Cu}$ pollution may start exerting ecological and 

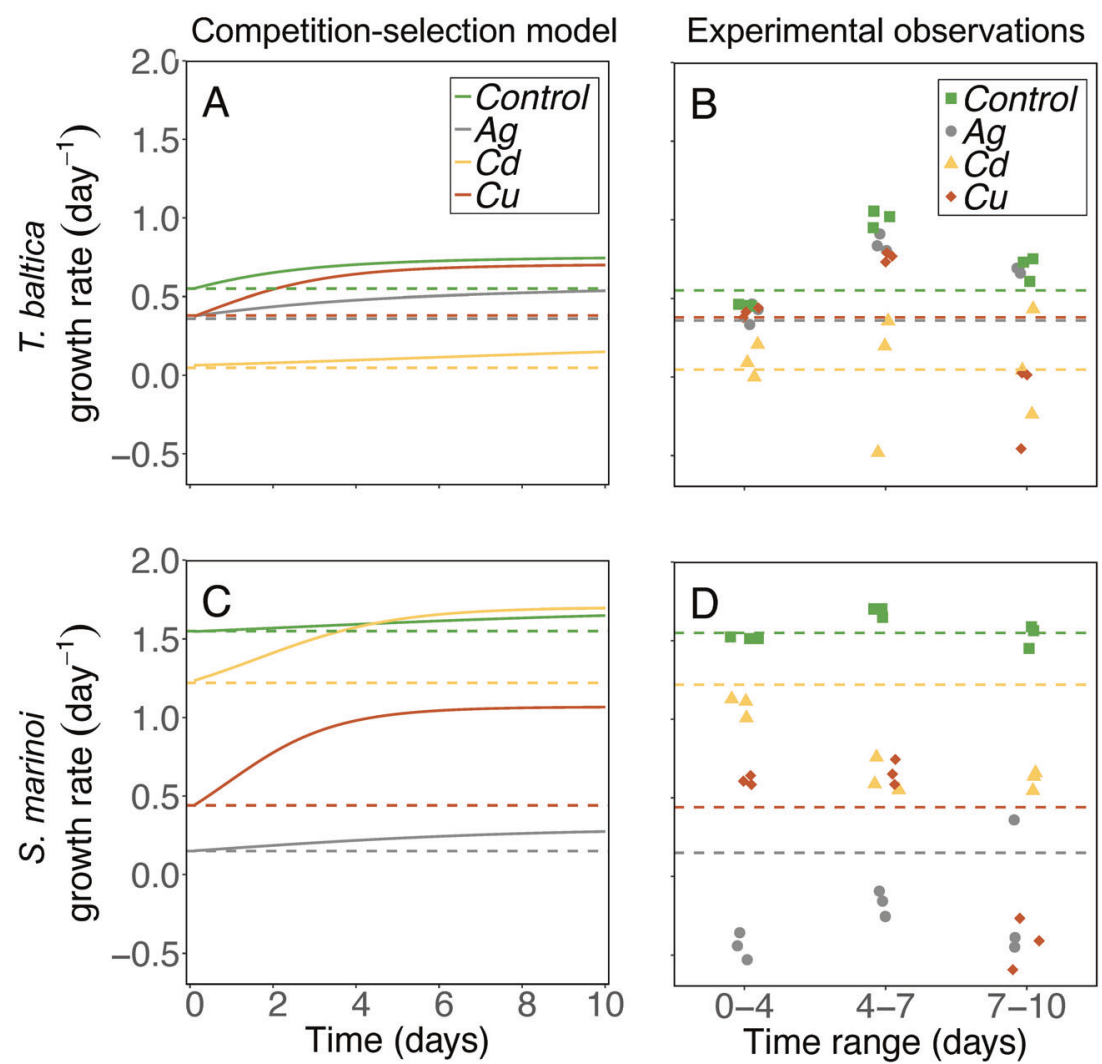

Fig. 5 The Competition-Selection model prediction and experimental observations of changes in growth rate under co-cultivation. Solid lines in $(\mathbf{A}, \mathbf{C})$ show the dose-response predicted modeled outcome and $(\mathbf{A}, \mathbf{B})$ the observed changes of species-specific growth rate during the competition experiment. As a point of reference, the species averages are shown as dashed lines across both panels. The upper panel of graphs (A, B) corresponds to T. baltica, and the lower (C, D) to S. marinoi. The Competition-Selection model assumes no interaction between species or strain and no acclimatization or development of chronic toxic effects, only selection based on variability in inhibition predictions from dose-response curves (A and $\mathbf{C})$. Observation data show specific growth rate observations computed based on microscopy observations on days $0,4,7$, and $10(N=3)$ of the competition experiment (B and $\mathbf{D})$. Note that statistical tests have been performed on inhibition data computed from growth rates as shown in (B and $\mathbf{D})$ (see Table 1).

evolutionary effects on diatoms in the Baltic Sea. The majority of observations in the Baltic Sea databases were within the 0.01-0.1 $\mu \mathrm{M}$ range, but $0.4 \%$ exceeded the threshold of $0.26 \mu \mathrm{M}$ (Fig. S6A). Out of 141 sample locations in the Baltic Sea, the $>0.26 \mu \mathrm{M}$ observations were distributed across nine locations (Fig. S6B). All sites were coastal (Sweden, Poland, Lithuania, and Germany) and close to $(<50 \mathrm{~km})$ or within major cities, river mouths, bays, or marinas (Fig. 1). There was high temporal variance in $\mathrm{Cu}$ concentrations, indicating that high $\mathrm{Cu}$ loading occurs in pulses. Seven of the nine highest recorded values were in spring (Jan-May: Table S2), coinciding with the timing of the spring diatom bloom.

\section{DISCUSSION}

\section{Lack of competitive interaction in co-culture}

Whether or not phytoplankton community interactions can be modeled based on mono-culture trait observations is contested [30$33,55]$, and likely taxon-specific. Deviations from expected growth patterns under co-cultivations have been attributed to differences in luxury consumption of nutrients [35], negative allelopathic chemical production [34], allelopathic stimulation of growth [30,56], physical cell-cell interactions [57], and extracellularly mediated programmed cell death at high densities [58]. In contrast, we largely succeeded in modeling the outcome of the co-cultivation experiment using individual strain traits, suggesting low levels of modulated growth due to competitive interactions between T. baltica and S. marinoi, at ecologically relevant cell densities.
A prerequisite for our model was the maintenance of nutrient replete and thereby exponential growth. If unaccounted for, nutrient limitation can be a major confounding parameter in experiments [49, 59]. Inarguably, nutrient limitation is an ecologically important condition and we agree that it would most likely modulate the competitive outcome both by favoring the species with highest affinity for the limiting nutrient [60] or causing increased toxic sensitivity $[16,61,62]$. Yet, building a model and designing an experiment that accounts for these effects, would require accounting for both nutrient availability and assimilation. This involves measuring strain specific nutrient uptake kinetics, as well as interactions between nutrient limitation and toxicity, and employing a chemostat culturing approach to maintain balanced nutrient-limited growth [49]. Hence, further research is needed to explore how nutrient limitation modulate competition under toxic metal stress.

\section{Variability in metal tolerance between strains and species}

Due to their large population sizes and high genetic diversity, phytoplankton have been suggested to evolve rapidly $[63,64]$. In accordance, we observed that predicted increase in species growth rate via strain selection was realized in the Control, Ag, and $\mathrm{Cu}$ treatments, highlighting that evolution of metal tolerance through selection on standing genetic diversity can occur on short timescales in diatoms (only 10-20 generations passed in the 10day experiment). Other artificial evolution experiments, mainly focused on climate-related conditions such as warming and elevated $p \mathrm{CO}_{2}$, have shown that there is potential for other 
Table 1. Relative (0-1) inhibition of growth rate during the competition experiment.

\begin{tabular}{|c|c|c|c|c|c|c|c|c|}
\hline \multirow[b]{2}{*}{ Inhibition } & \multicolumn{4}{|c|}{ Skeletonema marinoi } & \multicolumn{4}{|c|}{ Thalassiosira baltica } \\
\hline & Control & $\mathbf{A g}^{*}$ & $\mathbf{C d}^{*}$ & $\mathrm{Cu}$ & Control & Ag* & $\mathbf{C d}^{*}$ & $\mathbf{C u}$ \\
\hline Day $0-4$ & $0(0.004)$ & $1.29(0.057)$ & $0.29(0.043)$ & $0.6(0.019)$ & $0(0.012)$ & $0.1(0.15)$ & $0.78(0.23)$ & $0.1(0.068)$ \\
\hline Day 7-10 & $0(0.048)$ & $1.1(0.29)$ & $0.6(0.039)^{*}$ & $1.3(0.11)^{*}$ & $0(0.11)$ & $0.025(0.025)$ & $0.89(0.48)$ & $1.2(0.39)^{*}$ \\
\hline Average & 0 & 1.2 & 0.5 & 0.84 & 0 & 0.095 & 0.88 & 0.51 \\
\hline
\end{tabular}

Estimates of inhibition are based on microscopy observations on day $0,4,7$, and 10 , and the means (S.D.) are shown $(N=3)$. Linear mixed effects models identified all three factors (Metal, Time, and Species) as significant (all $p<0.0001$ ) and also interactions between Species $\times$ Metal $\left(\mathrm{F}_{(3,40),}, p<0.0001\right)$ and Metal $\times$ Time $\left(\mathrm{F}_{(6,40)}, p<0.0001\right)$, but not the Species $\times$ Time $\left(\mathrm{F}_{(2,40)}, p=0.73\right)$. Asterisk and bold-formatted metals $(\mathrm{Ag}$, $\mathrm{Cd}$, and $\mathrm{Cu})$ therefore indicate post hoc significant $(p>0.05)$ differences between the two species without considering Time effects. Asterisk and bold-formatted inhibition numbers indicate significant Time effect for Metals (compared with days 0-4).

phytoplankton species to evolve through selection on standing genetic diversity amongst strains [23, 55, 65]. Population wide studies have been performed for a wide range of phytoplankton traits, with the most common interpretation of the results being to compare averages between populations, and not evolutionary potential (but see $[25,66]$ ). Our findings stress the importance of interpreting intraspecific variation of populations through evolutionary modeling, and not statistical tests that compare changes in the mean (such as $t$-test and post hoc test associated with ANOVA or LME analysis). To this end, our modeling may be modified to include more species or strains, other types of response curves, or fluctuations in selection pressures along the response gradient.

Arguably, our study was limited in scope to only four strains of each species, far from the expected population size of phytoplankton (thousands of clones per bloom [67]). Hence, we are likely capturing only a fraction of the evolutionary potential of the two populations. Nevertheless, our observations regarding competitive response to $\mathrm{Cd}$ and $\mathrm{Ag}$ appear robust enough to represent the species, given the lack of overlap in tolerance towards these two metals. Regarding $\mathrm{Cu}$, we cannot rule out that random sampling effects confound our competitive prediction. However, we observed more variance in both growth and inhibition traits (trend in seven out of eight traits) in $T$. baltica compared to S. marinoi. Therefore, we expect that adding more strains to the population would lead to the discovery of more tolerant T. baltica compared to S. marinoi strains, in line with our competitive prediction for $\mathrm{Cu}$. Nevertheless, future evolutionary studies should strive to encompassed larger populations to gain a better understand the role of intraspecific diversity in shifting ecological interactions between diatom species. This can be achieved through either natural community mesocosm experiment or via high-throughput phenotyping combined with artificial evolution experiments.

\section{Variability in modes of toxicity among metals}

The three metals caused distinct patterns in modulation of species competition. Most strikingly, Cd completely inhibited T. baltica while S. marinoi continued to grow, while for Ag, the reverse effect was observed (Fig. 5). This is surprising since selection experiments on natural communities of microbes often show that selection for one metal causes co-selection for tolerance to other metals $[5,68,69]$. $\mathrm{Cd}$, unlike $\mathrm{Cu}$ and $\mathrm{Ag}$, is mutagenic to bacteria [70] and it is possible $T$. baltica is more sensitive to DNA damage than S. marinoi. The silica frustule changes we observed in both species under $\mathrm{Cd}$ stress may be deformities caused by disruption of the cell-cycle or silicification processes, which could have a mutagenic origin [43]. The slow development of Cd toxicity is in line with such an indirect mode of inhibition. Another possibility is that there was positive selection for certain morphotypes, a phenomenon that was recently observed in Phaeodactylum tricornutum, were an oval morphotype is more resistant to $\mathrm{Cd}$ due to differences in cell wall structural properties [71]. However, in our experiment fitness was expected to recover over time if there is strong selection for strain morphotypes, but this was not observed.

An expected challenge to our modeling effort was that metal toxicity would change over time, either due to chronic stress or physiological acclimatization. In our experiments, chronic stress was the more dominating of the two processes. The slow development of chronic toxicity towards $\mathrm{Cu}$ and $\mathrm{Cd}$ provides a challenge for utilizing acute dose-response data to predict longterm inhibition patterns. However, changes in species' biomass ratios could still be accurately predicted for $\mathrm{Cu}$ (Fig. 4A), since chronic toxicity affected both species similarly (Fig. 5). On the other hand, both growth rate and biomass ratios predictions were affected by chronic toxicity under Cd stress, since inhibition levels increased only in S. marinoi. We suggest that future modeling could be improved through parametrization of the timedependent (chronic) inhibition component. Another strategy could be to pre-acclimatize the cultures to toxic stress before experiments [15], although it is questionable if this is ecologically relevant for marine phytoplankton that generally experience pulses of toxicity associated with point sources of pollution from land run-off, ships, or marinas (Table S2: [11, 72]).

Phytoplankton have a remarkable acclimatization potential to abiotic stressors such as temperature, acidification, nutrient limitation, and irradiance changes [66, 73-75]. Our experiment, in line with previous observations [76], suggests that for toxic metal stress, the acclimatization processes are less important than the development of chronic stress. Undoubtedly, the cells still undergo some acclimatization process to metal stress, but our results suggest that this process may be rapid enough to be largely incorporated in the acute $72 \mathrm{~h}$ dose-responses. Metal exposure has been shown to trigger rapid (12-24 $\mathrm{h}$ ) reductions in phytoplankton transporter activity, production of phytochelators, and upregulation of oxidative stress responses in other microalgae species [41, 77, 78], which supports this conclusion.

\section{Copper toxicity in the Baltic Sea}

A relevant question to our laboratory study is whether Baltic Sea diatoms ever experience toxic $\mathrm{Ag}, \mathrm{Cd}$, and $\mathrm{Cu}$ concentrations in their ambient environment? In our Baltic Sea database search, we found no evidence $\mathrm{Cd}$ would reach concentrations that cause toxicity, and no data on Ag pollution. In contrast, we found reports of comparatively high $\mathrm{Cu}$ concentrations. Strict comparisons between environmental metal concentrations and culture predicted inhibition are difficult due to the strong chelation of $\mathrm{Cu}$ ions by compounds that are selectively removed and amended to the growth media. Further complicating factors such as nutrient limitation, stress from multiple metals, dissolved and particulate organic material, changes in salinity and inorganic ligand concentrations, also interact to modulate the toxicity experience 
by phytoplankton $[11,12,16,46,61,70]$. When we removed EDTA from the media, we observed Cu toxicity (EC05) at concentrations of $0.26 \mu \mathrm{M}$, which was lower than observational data at certain locations with high anthropogenic loading (Figs. 1, S6). Although this does not provide conclusive evidence, it suggests that Cu may have structural effects on local diatom populations in the Baltic Sea.

In our laboratory experiments, we observed that $\mathrm{Cu}$ stress causes a long-term reduction in S. marinoi fitness in competition with $T$. baltica. Although it is possible that other diatom species are more or less sensitive to $\mathrm{Cu}$, these two species comprise about $50 \%$ of the standing diatom biomass in Baltic Sea spring blooms (Fig. S1). We therefore expect that S. marinoi would suffer a competitive disadvantage at toxic $\mathrm{Cu}$ concentrations. It may explain why $S$. marinoi went locally extinct at the copper mining exposed Gåsfjärden inlet from the 1600s to the late 1900s [17], and has evolved $\mathrm{Cu}$ tolerance during later re-colonization [16]. Although we cannot provide further evidence of drivers behind such historical events, our observations here warrant further field research into marine areas that experience high Cu loading (e.g., Baltic Sea locations identified in Table S2). Such studies could provide direct evidence for evolutionary and ecological effects of metal pollution on coastal phytoplankton communities.

\section{CONCLUSIONS}

We have shown that different metal stress can modulate diatom species competition in opposite directions ( $\mathrm{Cd}$ and $\mathrm{Ag}$ ), suggesting that the mechanism conferring tolerance differs between both species and metals. Based on S. marinoi and T. baltica, it appears possible to utilize mono-culture fitness measurements to model diatom species competition, opening an avenue to make ecological and evolutionary predictions based on toxicological laboratory observation. However, relying on single microalgal strains, or population averages, to make species generalizations can lead to incorrect and largely random ecological conclusions. Instead, it is necessary to quantify and account for intraspecific trait variance to successfully predict how toxic stress affects microbial systems. A formidable future challenge is how to sufficiently account for standing genetic variation within the enormous population sizes of eukaryotic phytoplankton.

\section{REFERENCES}

1. Blowes SA, Supp SR, Antão LH, Bates A, Bruelheide H, Chase JM, et al. The geography of biodiversity change in marine and terrestrial assemblages. Science. 2019;366:339-45.

2. Blanck H. A critical review of procedures and approaches used for assessing pollution-induced community tolerance (PICT) in biotic communities. Hum Ecol Risk Assess. 2002;8:1003-34.

3. Tlili A, Berard A, Blanck H, Bouchez A, Cássio F, Eriksson KM, et al. Pollutioninduced community tolerance (PICT): towards an ecologically relevant risk assessment of chemicals in aquatic systems. Freshwat Biol. 2016;61:2141-51.

4. Duxbury T. Ecological aspects of heavy metal responses in microorganisms. In: Marshall KC, editor. Adv Microb Ecol. New York, USA: Springer; 1985. pp. 185-235.

5. Carlson HK, Price MN, Callaghan M, Aaring A, Chakraborty R, Liu H, et al. The selective pressures on the microbial community in a metal-contaminated aquifer. ISME J. 2019;13:937-49.

6. Stepanauskas R, Glenn TC, Jagoe $\mathrm{CH}$, Tuckfield RC, Lindell AH, McArthur J. Elevated microbial tolerance to metals and antibiotics in metal-contaminated industrial environments. Environ Sci Technol. 2005;39:3671-8.

7. Gans J, Wolinsky M, Dunbar J. Computational improvements reveal great bacterial diversity and high metal toxicity in soil. Science. 2005;309:1387-90.

8. Falkowski PG, Barber RT, Smetacek VV. Biogeochemical Controls and Feedbacks on Ocean Primary Production. Science. 1998;281:200-7.

9. Field $\mathrm{CB}$, Michael JB, Randerson JT, Falkowski P. Primary production of the biosphere: integrating terrestrial and oceanic components. Science. 1998;281:237-40.

10. Reusch TB, Dierking J, Andersson HC, Bonsdorff E, Carstensen J, Casini M, et al. The Baltic Sea as a time machine for the future coastal ocean. Sci Adv. 2018;4: eaar8195.
11. Lehtonen KK, Bignert A, Bradshaw C, Broeg K, Schiedek D. Chemical pollution and ecotoxicology. In: Snoeijs-Leijonmalm PSH, Radziejewska T, editors. Biological oceanography of the Baltic Sea. Dordrecht, The Netherlands: Springer Nature; 2017. pp. 547-89.

12. Moffett JW, Brand LE, Croot PL, Barbeau KA. Cu speciation and cyanobacterial distribution in harbors subject to anthropogenic $\mathrm{Cu}$ inputs. Limnol Oceanogr. 1997;42:789-99.

13. Echeveste P, Agusti S, Tovar-Sanchez A. Toxic thresholds of cadmium and lead to oceanic phytoplankton: cell size and ocean basin-dependent effects. Environ Toxicol Chem. 2012;31:1887-94.

14. Tsiola A, Toncelli C, Fodelianakis S, Michoud G, Bucheli TD, Gavriilidou A, et al. Low-dose addition of silver nanoparticles stresses marine plankton communities. Environ Sci Nano. 2018;5:1965-80.

15. Brand LE, Sunda WG, Guillard RR. Reduction of marine phytoplankton reproduction rates by copper and cadmium. J Exp Mar Biol Ecol. 1986;96:225-50.

16. Andersson B, Godhe A, Filipsson HL, Rengefors K, Berglund O. Differences in metal tolerance among strains, populations, and species of marine diatomsimportance of exponential growth for quantification. Aquat Toxicol. 2020;226:105551.

17. Ning W, Nielsen A, Ivarsson LN, Jilbert T, Åkesson C, Slomp C, et al. Anthropogenic and climatic impacts on a coastal environment in the Baltic Sea over the last 1000 years. Anthropocene. 2018;21:66-79.

18. Novotny A, Zamora-Terol S, Winder M. DNA metabarcoding reveals trophic niche diversity of micro and mesozooplankton species. Proc $R$ Soc $B$. 2021;288:20210908.

19. Horvatić J, Peršić V. The effect of $\mathrm{Ni}^{2+}, \mathrm{Co}^{2+}, \mathrm{Zn}^{2+}, \mathrm{Cd}^{2+}$ and $\mathrm{Hg}^{2+}$ on the growth rate of marine diatom Phaeodactylum tricornutum Bohlin: microplate growth inhibition test. Bull Environ Contam Toxicol. 2007;79:494-8.

20. Terseleer N, Bruggeman J, Lancelot C, Gypens N. Trait-based representation of diatom functional diversity in a plankton functional type model of the eutrophied southern North Sea. Limnol Oceanogr. 2014;59:1958-72.

21. Litchman E, Klausmeier CA, Schofield OM, Falkowski PG. The role of functional traits and trade-offs in structuring phytoplankton communities: scaling from cellular to ecosystem level. Ecol Lett. 2007;10:1170-81.

22. Ehrlich E, Kath NJ, Gaedke U. The shape of a defense-growth trade-off governs seasonal trait dynamics in natural phytoplankton. ISME J. 2020;14:1451-62.

23. Lohbeck KT, Riebesell U, Reusch TB. Adaptive evolution of a key phytoplankton species to ocean acidification. Nat Geosci. 2012;5:346.

24. Gross S, Kourtchenko O, Rajala T, Andersson B, Fernandez L, Blomberg A, et al. Optimization of a high-throughput phenotyping method for chain-forming phytoplankton species. Limnol Oceanogr Methods. 2017;16:57-67.

25. Rynearson TA, Armbrust EV. DNA fingerprinting reveals extensive genetic diversity in a field population of the centric diatom Ditylum brightwellii. Limnol Oceanogr. 2000;45:1329-40.

26. Kremp A, Oja J, LeTortorec AH, Hakanen P, Tahvanainen P, Tuimala J, et al. Diverse seed banks favour adaptation of microalgal populations to future climate conditions. Environ Microbiol. 2016;18:679-91.

27. Sjöqvist C, Godhe A, Jonsson PR, Sundqvist L, Kremp A. Local adaptation and oceanographic connectivity patterns explain genetic differentiation of a marine diatom across the North Sea-Baltic Sea salinity gradient. Mol Ecol. 2015;24:2871-85.

28. Rengefors K, Logares R, Laybourn-Parry J, Gast RJ. Evidence of concurrent local adaptation and high phenotypic plasticity in a polar microeukaryote. Environ Microbiol. 2015;17:1510-9.

29. Ajani PA, Petrou K, Larsson ME, Nielsen DA, Burke J, Murray SA. Phenotypic trait variability as an indication of adaptive capacity in a cosmopolitan marine diatom. Environ Microbiol. 2020;23:207-23.

30. Collins S, Schaum CE. Diverse strategies link growth rate and competitive ability in phytoplankton responses to changes in $\mathrm{CO}_{2}$ levels. bioRxiv. 2019. https://doi. org/10.1101/651471.

31. Baert JM, De Laender F, Sabbe K, Janssen CR. Biodiversity increases functional and compositional resistance, but decreases resilience in phytoplankton communities. Ecology. 2016;97:3433-40.

32. Tatters AO, Roleda MY, Schnetzer A, Fu F, Hurd CL, Boyd PW, et al. Short-and long-term conditioning of a temperate marine diatom community to acidification and warming. Philos Trans R Soc Lond B Biol Sc. 2013;368:20120437.

33. Collins $\mathrm{S}$. Competition limits adaptation and productivity in a photosynthetic alga at elevated $\mathrm{CO}_{2}$. Proc R Soc B. 2011;278:247-55.

34. Legrand C, Rengefors K, Fistarol GO, Graneli E. Allelopathy in phytoplanktonbiochemical, ecological and evolutionary aspects. Phycologia. 2003;42:406-19.

35. Powell N, Shilton AN, Pratt S, Chisti Y. Factors influencing luxury uptake of phosphorus by microalgae in waste stabilization ponds. Environ Sci Technol. 2008;42:5958-62.

36. OECD. Test no. 201: alga, growth inhibition test. 2006. https://www.oecd-ilibrary. org/content/publication/9789264069923-en. 
37. Anderson SI, Rynearson TA. Variability approaching the thermal limits can drive diatom community dynamics. Limnol Oceanogr. 2020;65:1961-73.

38. Spilling K, Markager S. Ecophysiological growth characteristics and modeling of the onset of the spring bloom in the Baltic Sea. J Mar Syst. 2008;73:323-37.

39. Behrenfeld MJ. Abandoning Sverdrup's Critical Depth Hypothesis on phytoplankton blooms. Ecology. 2010;91:977-89.

40. Follows MJ, Dutkiewicz S, Grant S, Chisholm SW. Emergent biogeography of microbial communities in a model ocean. Science. 2007;315:1843-6.

41. Abner B, Morel F, Moffett J. Trace metal control of phytochelatin production in coastal waters. Limnol Oceanogr. 1997;42:601-8.

42. Behra R, Genoni GP, Joseph AL. Effect of atrazine on growth, photosynthesis, and between-strain variability in scenedesmus subspicatus (Chlorophyceae). Arch Environ Contamin Toxicol. 1999;37:36-41.

43. Tiam SK, Lavoie I, Doose C, Hamilton PB, Fortin C. Morphological, physiological and molecular responses of Nitzschia palea under cadmium stress. Ecotoxicology. 2018;27:675-88

44. Härnström K, Ellegaard M, Andersen TJ, Godhe A. Hundred years of genetic structure in a sediment revived diatom population. Proc Natl Acad Sci USA. 2011;108:4252-7.

45. Guillard RR Culture of phytoplankton for feeding marine invertebrates. In: Smith $\mathrm{WL}$, Chanley $\mathrm{MH}$, editors. Culture of marine invertebrate animals. Boston, MA: Springer; 1975. pp. 29-60.

46. Leal PP, Hurd CL, Sander SG, Armstrong E, Roleda MY. Copper ecotoxicology of marine algae: a methodological appraisal. Chem Ecol. 2016;32:786-800.

47. Hillebrand H, Dürselen CD, Kirschtel D, Pollingher U, Zohary T. Biovolume calculation for pelagic and benthic microalgae. J Phycol. 1999;35:403-24.

48. Schreiber U. Chlorophyll fluorescence: new instruments for special applications. In: Garab G, editor. Photosynthesis: mechanisms and effects. Springer, Dordrecht: Springer; 1998. pp. 4253-8.

49. Maclntyre HL, Cullen JJ. Using cultures to investigate the physiological ecology of microalgae. In Andersen RA, editor. Algal culturing techniques. Burlington, Mass: Elsevier; 2005. p. 287-326.

50. Caceres C, Taboada FG, Höfer J, Anadon R. Phytoplankton growth and microzooplankton grazing in the subtropical Northeast Atlantic. Plos ONE. 2013;8:e69159.

51. R Core Team. R: a language and environment for statistical computing. Vienna, Austria: R Foundation for Statistical Computing; 2018. https://www.R-project.org/.

52. Ritz C, Baty F, Streibig JC, Gerhard D. Dose-response analysis using R. PloS ONE. 2015;10:e0146021.

53. Wickham H. ggplot2. WIREs Comp Stat. 2011;3:180-5.

54. Pinheiro J, Bates D, DebRoy S, Sarkar D, The R Core Team. nlme: Linear and Nonlinear Mixed Effects Models [Internet]. 2021. Available from: https://CRAN.Rproject.org/package $=$ nlme.

55. Wolf KK, Romanelli E, Rost B, John U, Collins S, Weigand H, et al. Company matters: the presence of other genotypes alters traits and intraspecific selection in an Arctic diatom under climate change. Glob Change Biol. 2019;25:2869-84.

56. Venuleo $M$, Raven JA, Giordano $M$. Intraspecific chemical communication in microalgae. N Phytol. 2017;215:516-30.

57. Esteves-Ferreira AA, Inaba M, Obata T, Fort A, Fleming GT, Araújo $W L$, et al. A novel mechanism, linked to cell density, largely controls cell division in Synechocystis. Plant Physiol. 2017;174:2166-82.

58. Gallo C, d'Ippolito G, Nuzzo G, Sardo A, Fontana A. Autoinhibitory sterol sulfates mediate programmed cell death in a bloom-forming marine diatom. Nat Commun. 2017:8:1-11.

59. Gresham D, Dunham MJ. The enduring utility of continuous culturing in experimental evolution. Genomics. 2014;104:399-405.

60. Descamps-Julien B, Gonzalez A. Stable coexistence in a fluctuating environment: an experimental demonstration. Ecology. 2005;86:2815-24.

61. Wang NX, Huang B, Xu S, Wei ZB, Miao AJ, Ji R, et al. Effects of nitrogen and phosphorus on arsenite accumulation, oxidation, and toxicity in Chlamydomonas reinhardtii. Aquat Toxicol. 2014;157:167-74.

62. Lee J-W, Helmann JD. Functional specialization within the Fur family of metalloregulators. BioMetals. 2007;20:485.

63. Reusch TB, Boyd PW. Experimental evolution meets marine phytoplankton. Evolution. 2013;67:1849-59.

64. Walworth NG, Zakem EJ, Dunne JP, Collins S, Levine NM. Microbial evolutionary strategies in a dynamic ocean. Proc Natl Acad Sci USA. 2020;117:5943-8.

65. Schaum C-E, Barton S, Bestion E, Buckling A, Garcia-Carreras B, Lopez P, et al. Adaptation of phytoplankton to a decade of experimental warming linked to increased photosynthesis. Nat Ecol Evol. 2017;1:1-7.

66. Collins S, Rost B, Rynearson TA. Evolutionary potential of marine phytoplankton under ocean acidification. Evol Appl. 2014;7:140-55.

67. Rynearson TA, Armbrust EV. Genetic differentiation among populations of the planktonic marine diatom ditylum brightwellii (bacillariophyceae) 1. J Phycol. 2004;40:34-43.
68. Soldo D, Behra R. Long-term effects of copper on the structure of freshwater periphyton communities and their tolerance to copper, zinc, nickel and silver. Aquat Toxicol. 2000;47:181-9.

69. Stokes PM. Multiple metal tolerance in copper tolerant green algae. J Plant Nutr 1981;3:667-78.

70. Lemire JA, Harrison JJ, Turner RJ. Antimicrobial activity of metals: mechanisms, molecular targets and applications. Nat Rev Microbiol. 2013;11:371-84.

71. Ma J, Zhou B, Chen F, Pan K. How marine diatoms cope with metal challenge: Insights from the morphotype-dependent metal tolerance in Phaeodactylum tricornutum. Ecotoxicol Environ Saf. 2020;208:111715.

72. Egardt J, Larsen MM, Lassen P, Dahllöf I. Release of PAHs and heavy metals in coastal environments linked to leisure boats. Mar Pollut Bull. 2018;127:664-71.

73. Falkowski PG, LaRoche J. Acclimation to spectral irradiance in algae. J Phycol. 1991;27:8-14.

74. Beardall J, Young E, Roberts S. Approaches for determining phytoplankton nutrient limitation. Aquat Sci. 2001;63:44-69.

75. Boyd PW, Rynearson TA, Armstrong EA, Fu F, Hayashi K, Hu Z, et al. Marine phytoplankton temperature versus growth responses from polar to tropical waters-outcome of a scientific community-wide study. PloS ONE. 2013;8:e63091.

76. Johnson HL, Stauber JL, Adams MS, Jolley DF. Copper and zinc tolerance of two tropical microalgae after copper acclimation. Environ Toxicol. 2007;22:234-44.

77. Cid A, Herrero C, Torres E, Abalde J. Copper toxicity on the marine microalga Phaeodactylum tricornutum: effects on photosynthesis and related parameters. Aquat Toxicol. 1995;31:165-74.

78. Masmoudi S, Nguyen-Deroche N, Caruso A, Ayadi H, Morant-Manceau A, Tremblin $\mathrm{G}$, et al. Cadmium, copper, sodium and zinc effects on diatoms: from heaven to hell-a review. Cryptogam Algol. 2013;34:185-225.

\section{ACKNOWLEDGEMENTS}

The Captain and the crew of r/v Electra af Askö and Johan Burman and Kotaro Hirose for sediment sampling assistance. Bengt Karlson, Maria Karlberg, Malin Olofsson, and Johannes Johansson at the Swedish Meteorological and Hydrological Institute (SMHI) for organizing a workshop on how to process their plankton monitoring data. Finn Baumgartner (Geological Survey of Sweden (SGU)) and Carina Pålsson (Kalmar County Administrative Board), for correspondence and suggestions on databases containing copper measurement data. Kerstin Johannesson, for critical reviewing and feedback during the preparation of the manuscript, as well as comments from two anonymous reviewers and Senior Editor Frank Stewart.

\section{AUTHOR CONTRIBUTIONS}

AG and BA designed the experiment, $A G$ and HLF performed the field work, BA conducted the laboratory work, analyzed the data, processed the phytoplankton monitoring data, and drafted the first version of the manuscript. LE provided taxonomic identification of Thalassiosira baltica. $\mathrm{LZ}$ assembled and visualized the copper monitoring data. $\mathrm{OB}, \mathrm{KR}, \mathrm{HLF}, \mathrm{LZ}, \mathrm{LE}$, and $\mathrm{BA}$ all contributed to writing the final paper. AG is included posthumously.

\section{FUNDING}

This project was funded by the Swedish Research Council for Environment, Agricultural Sciences and Spatial Planning (FORMAS) grant number 2016-00594, and the Oscar and Lili Lamm Foundation grant number FO2018-0042.

\section{COMPETING INTERESTS}

The authors declare no competing interests.

\section{ADDITIONAL INFORMATION}

Supplementary information The online version contains supplementary material available at https://doi.org/10.1038/s41396-021-01092-9.

Correspondence and requests for materials should be addressed to B.A.

Reprints and permission information is available at http://www.nature.com/ reprints

Publisher's note Springer Nature remains neutral with regard to jurisdictional claims in published maps and institutional affiliations. 
(c) (i) Open Access This article is licensed under a Creative Commons Attribution 4.0 International License, which permits use, sharing, adaptation, distribution and reproduction in any medium or format, as long as you give appropriate credit to the original author(s) and the source, provide a link to the Creative Commons license, and indicate if changes were made. The images or other third party material in this article are included in the article's Creative Commons license, unless indicated otherwise in a credit line to the material. If material is not included in the article's Creative Commons license and your intended use is not permitted by statutory regulation or exceeds the permitted use, you will need to obtain permission directly from the copyright holder. To view a copy of this license, visit http://creativecommons. org/licenses/by/4.0/.

(c) The Author(s) 2021 